\title{
Left Middle Anterior Fibromuscular Stroma of Prostate
}

National Cancer Institute

\section{Source}

National Cancer Institute. Left Middle Anterior Fibromuscular Stroma of Prostate. NCI

Thesaurus. Code C128599.

The portion of the fibromuscular stroma of the prostate that is located on the anatomical left side of the middle division of the anterior lobe. 